\title{
Commentary on High-Performance Computing and Neural and Physiological Processes: Focusing on the problem-solving process
}

\author{
JAY SAMUELS \\ University of Minnesota, Minneapolis, Minnesota
}

\begin{abstract}
The presentations by James A. Anderson (Anderson \& Sutton, 1997) and Samuel Williamson (Gençer $\&$ Williamson, 1997) were indicative of a research effort focused on the real life psychological processes as opposed to the outcomes. The mental twists and turns in solving problems, often hidden from a learner, if shared, may demystify the learning process. This process-oriented psychological research should receive continued encouragement.
\end{abstract}

In Samuel Williamson's (Gençer \& Williamson, 1997) demonstration, the temporal and spatial information from the electromagnetic fields of the cortex was used to detect some of the finer cognitive processes-for example, whether memory was involved in the task. In James A. Anderson's (Anderson \& Sutton, 1997) presentation, incorrect answer patterns indicative of some systematic thinking processes were identified in an arithmetic operation-namely, multiplication. Those presentations both represented an effort to pursue and identify the real-life psychological processes as opposed to outcomes.

The discussion following these two presentations centered on the fact that we still seem to focus on the outcome instead of the process of everyday psychological phenomena. A case in point is the teaching of mathematics. This was interesting from the perspective of a psychologist who studies learning, thinking, and the teaching of difficult concepts. Patrick Suppes commented that, in his opinion, the way we teach mathematical and scientific concepts to our students seems to be wrong. He had observed that regardless of the level of knowledge or sophistication of the students whom we teach, we tend to take the end product of a long period of thinking and analysis and to present just the final conclusions to the students. This simple observation - namely, that showing only the end product might be wrong - met with general agreement from other members of the audience. The audience agreed that the long road that we take as we try to find solutions to problems, the mental twists and turns that we go through, the mental effort that is part of the process leading to the end point is hidden from the eyes of our students. In essence, the footprints that mark the sands of human problem solving, invention, and creativity are obliterated.

But, what harm can possibly come from simply sharing with students the end points- the solutions - of our at-

Correspondence concerning this article should be addressed to J. Samuels, Department of Educational Psychology, 211 Burton Hall, 178 Pillsbury Dr., S.E., Minneapolis, MN 55455 (e-mail: samue001@, maroon.tc.umn.edu). tempts to solve problems? What negative effects come from obliterating the footprints from the sands of cognitive processing? One harmful effect is that we perpetuate to our students the "myth of genius," the idea that only the truly gifted are capable of having important insights, and that these insights come instantly like a flash of lightning on a dark night. What we fail to show our students is the fact that these insights may come only after an extended period of time devoted to solving intellectual problems. For example, in the movie Amadeus, the great musician Mozart is shown in the act of creating music of lasting quality while he casually interacts with the members of his family. When his wife tries to sell his music to Salieri, a musician of lesser talents, Salieri is amazed at the quality of what he is offered and asks Mozart's wife if there are any working papers. "No," she says. "His music comes fully developed on the first writing and does not need to be changed because he is inspired." (Inspiration means that God has breathed creative genius into a person.) This is a wonderful story told by the Hollywood film industry, but it is not accurate. A search of Mozart's musical writing reveals that, contrary to the myth that he could create great works on the spot while engaging in other mundane activities, he had detailed working scores that he used and edited in his efforts to create works of lasting quality.

Another story perpetuating the myth of genius is the story of how Archimedes, the great Greek mathematician and inventor, discovered "Archimedes' principle," that an object immersed in fluid will lose in weight an amount equal to the weight of the fluid being displaced. The problem on which he was working was that of finding a practical way to determine whether a piece of metal that looked like gold was actually the precious metal or a fake. The legend surrounding his life was that one hot day he took his clothes off and sank into a tub of water to cool off. The tub was filled with water up to the brim and as his body sank into the tub he noticed the water spilling on to the floor. As the water spilled he realized that the volume of the water that overflowed would be the same as the volume of his body. In a flash, he realized that he had the so- 
lution to his problem on how to tell whether a metal was real gold or fool's gold. He was so excited by his discovery that he forgot to dress and ran naked into the street, shouting "Eureka!" [I have found it.]

Again, the truth is that Archimedes was a highly educated man and a noted scientist who had been looking for a solution to his problem for an extended period of time. Although his insight and solution occurred suddenly, it was made possible only by the fact that he was searching for an answer and had the knowledge and training that made the discovery possible. Many other people who lacked the background knowledge that Archimedes possessed had seen water spilling on the floor from a tub without ever being able to make a useful application of the observation. In essence, the flash of insight that led to Archimedes' principle was years in the making.

What I have tried to show is that one negative effect of showing only the end product of scientific and mathematical thinking to students is that it perpetuates the "myth of genius," that it gives students the idea that only some fortunate few are born with the spark of intellectual power that enables them to create works of great art and to solve important scientific problems almost effortlessly. Our students must be educated so that they realize that creative breakthroughs can come to anyone who is well trained and willing to commit one's training and knowledge for an extended period of time toward the solution of a problem. Perhaps the model we should be using with students is the one provided by the Wright brothers, ordinary men who were the owners of a bicycle shop.

My final point, which grows out of the audience's comments, is that learning is a process as well as a product.
We have all heard the expression, "If you give a person a fish, you provide food for only one meal, but if you teach a person how to fish, you provide the person with the ability to provide food for a lifetime." As a starting point to one of the goals of scientific literacy, we want our students to know the answers to questions that deal with "who discovered what, and when, and how we can use this discovery." But this kind of knowledge is no more than giving a person a fish. To take this one step further, we also want our students to know "how the discovery was made and what kind of thinking went into the process." When we do this, we help our students learn how to think and solve problems on their own. In the end, we want to bring an end to the myth of creative genius, which perpetuates the idea that only those who are inspired can find the solutions to important problems. We should encourage students to believe that the creative solution to most problems is within the grasp of anyone who has the background, training, and motivation to invest time and effort in finding answers to important questions, just as I sincerely hope that we further the psychological research in the direction of understanding the "footprints of problem solving" as opposed to its outcome.

\section{REFERENCES}

ANDERSON, J., \& SutTon, P. (1997). If we compute faster, do we understand better? Behavior Research Methods, Instruments, \& Computers, 29, 67-77.

Gençer, N. G., \& Williamson, S. J. (1997). Magnetic source images of human brain functions. Behavior Research Methods, Instruments, \& Computers, 29, 78-83. 